\title{
Homogeneous nucleation rates of nitric acid dihydrate (NAD) at simulated stratospheric conditions - Part II: Modelling
}

\author{
O. Möhler, H. Bunz, and O. Stetzer \\ Forschungszentrum Karlsruhe, Institute for Meteorology and Climate Research (IMK-AAF), Germany
}

Received: 23 December 2005 - Published in Atmos. Chem. Phys. Discuss.: 28 March 2006

Revised: 6 July 2006 - Accepted: 11 July 2006 - Published: 24 July 2006

\begin{abstract}
Activation energies $\Delta G_{\text {act }}$ for the nucleation of nitric acid dihydrate (NAD) in supercooled binary $\mathrm{HNO}_{3} / \mathrm{H}_{2} \mathrm{O}$ solution droplets were calculated from volume-based nucleation rate measurements using the AIDA (Aerosol, Interactions, and Dynamics in the Atmosphere) aerosol chamber of Forschungszentrum Karlsruhe. The experimental conditions covered temperatures T between 192 and 197 K, NAD saturation ratios $S_{\mathrm{NAD}}$ between 7 and 10, and nitric acid molar fractions of the nucleating sub-micron sized droplets between 0.26 and 0.28 . Based on classical nucleation theory, a new parameterisation for $\Delta G_{\mathrm{act}}=A \times\left(T \ln S_{\mathrm{NAD}}\right)^{-2}+B$ is fitted to the experimental data with $A=2.5 \times 10^{6} \mathrm{kcal}$ $\mathrm{K}^{2} \mathrm{~mol}^{-1}$ and $B=11.2-0.1(T-192) \mathrm{kcal} \mathrm{mol}^{-1}$. $A$ and $B$ were chosen to also achieve good agreement with literature data of $\Delta G_{\text {act }}$. The parameter $A$ implies, for the temperature and composition range of our analysis, a mean interface tension $\sigma_{s l}=51 \mathrm{cal} \mathrm{mol}^{-1} \mathrm{~cm}^{-2}$ between the growing NAD germ and the supercooled solution. A slight temperature dependence of the diffusion activation energy is represented by the parameter $B$. Investigations with a detailed microphysical process model showed that literature formulations of volume-based (Salcedo et al., 2001) and surface-based (Tabazadeh et al., 2002) nucleation rates significantly overestimate NAD formation rates when applied to the conditions of our experiments.
\end{abstract}

\section{Introduction}

Polar stratospheric cloud (PSC) particles play a wellrecognized role in the Antarctic and Arctic stratospheric ozone loss because they act as micro-reactors for heterogeneous activation of halogen reservoir species (Peter, 1997; Solomon, 1999). The main particle types in PSCs are (1)

Correspondence to: O. Möhler

(ottmar.moehler@imk.fzk.de) ternary solution droplets (STS) of water, sulphuric acid, and nitric acid, (2) ice particles, and (3) solid hydrates of nitric acid, either nitric acid dihydrate (NAD) or nitric acid trihydrate (NAT). The different PSC types were extensively investigated in remote sensing studies as well as in situ aircraft and balloon measurements. The equilibrium composition of STS particles can be calculated as function of temperature and relative humidity with well advanced thermodynamic models (Carslaw et al., 1995; Clegg et al., 1998). Approved and well developed concepts are also available to calculate, as function of temperature and molar composition, the formation rate of ice in STS particles at stratospheric conditions (Jensen et al., 1991; Koop et al., 2000). Solid nitric acid particles are of particular importance for correctly assessing the efficiency of polar ozone loss. Compared to ice and STS, the nitric acid hydrates are thermodynamically more stable, i.e., exist at higher temperatures, grow to larger sizes than STS particles, and have the potential for vertical transport of nitric acid which affects the ozone depletion chemistry (Waibel et al., 1999).

Despite their importance for polar ozone loss, knowledge of formation pathways and exact compositions of nitric acid hydrate particles in the polar stratosphere is still fragmentary. While recent field studies give direct evidence that NAT exists in PSCs (Voigt et al., 2000; Fahey et al., 2001; Brooks et al., 2003; Deshler et al., 2003; Voigt et al., 2005), laboratory investigations revealed the metastable NAD to nucleate in STS and binary water/nitric acid droplets at stratospheric temperatures (Disselkamp et al., 1996; Prenni et al., 1998; Bertram and Sloan, 1998a; Bertram et al., 2000; Salcedo et al., 2000, 2001; Knopf et al., 2002; Stetzer et al., 2006). Tizek et al. (2002) identified two metastable forms of the dihydrate, $\alpha$-NAD and $\beta$-NAD, after annealing amorphous nitric acid samples of variable molar composition. The less stable phase $\alpha$-NAD preferentially nucleated at lower temperatures and nitric acid molar ratios less than 0.3 .

Published by Copernicus GmbH on behalf of the European Geosciences Union. 
The direct crystallisation to NAT was in some studies only observed at temperatures below $180 \mathrm{~K}$ and saturation ratios of gas-phase nitric acid with respect to NAT larger than 45 (Bertram and Sloan, 1998b; Salcedo et al., 2001). Such low temperatures and high saturation ratios are not reached in synoptic-scale PSCs. Therefore, the contribution of homogeneous nucleation to the direct formation of NAT particles in PSCs is difficult to assess from the available laboratory studies.

Up to now it is not clear whether NAT or NAD particles can directly be formed by homogeneous nucleation of supercooled STS droplets in the polar stratosphere. Irie and Kondo (2003) explained observations of PSC formation and denitrification in the Arctic winter 1996/1997 by process model studies along back-trajectories assuming either homogeneous NAD nucleation followed by conversion to NAT particles or direct nucleation of NAT. Drdla and Browell (2004) concluded from a microphysical modelling study of the Arctic winter 1999-2000 that homogeneous NAD and NAT nucleation are not sufficient to explain the observed solid phase PSC formation and denitrification. Alternatively it was suggested that nitric acid hydrates may nucleate on ice particles formed in mountain-wave PSCs (Carslaw et al., 1999; Voigt et al., 2003). Remote sensing measurements with the MIPAS instrument on Envisat (Höpfner et al., 2006) showed that mountain wave activity with ice cloud formation triggered the formation of NAT clouds in the Antarctic winter 2003. Luo et al. (2003) suggested extremely high NAT supersturations in mountain wave PSCs to induce NAT nucleation. Other studies argue that NAT particles may nucleate directly from STS clouds without mountain-wave activity and ice cloud formation in advance (Irie et al., 2004; Pagan et al., 2004; Larsen et al., 2004) or speculate that nitric acid hydrates form heterogeneously on solid nuclei (Voigt et al., 2005 ) originating from e.g. meteor ablation (Curtius et al., 2005).

For the quantitative evaluation of homogeneous nucleation the classical nucleation theory provides a relation between the nucleation rate and the activation energy which controls the rate of stable solid germs to form and grow in the supercooled liquid. Salcedo et al. (2001) calculated activation energies from various data sets of NAD and NAT nucleation rates and suggested a linear equation to approximate the activation energy for NAD and NAT nucleation as function of the respective saturation ratios. These linear fits also considered data from cooled flow tube studies (Bertram and Sloan, 1998a,b) but disregarded data sets from earlier settling chamber studies (Disselkamp et al., 1996; Prenni et al., 1998) which disagreed to the linear relation. Tabazadeh et al. (2002) re-analysed all available literature data sets for NAD and NAT nucleation rates which have been measured for solution droplets of different size and surface-to-volume ratio, and obtained better agreement between the nucleation rates if the crystallisation of the solid hydrate was formulated as a surface induced process. Based on this result, Tabazadeh et al. (2002) suggested another linear approximation for the activation energy of the surface induced crystallisation as function of the temperature and the nitric acid molar fraction of the nucleating solution droplets.

The linear approximations for the activation energy of volume-based NAT and NAD nucleation (Salcedo et al., 2001) were in some studies extrapolated to stratospheric conditions in order to explain field observations of PSCs (Tabazadeh et al., 2001; Irie and Kondo, 2003). Knopf et al. (2002) measured lower limits for the activation energies of NAD and NAT nucleation and argued that linear equations as function of the saturation ratio are not appropriate to estimate the activation energy of nitric acid hydrate formation especially if they need to be extrapolated to conditions prevailing in PSCs. This caused a controversial debate about the interpretation of laboratory studies of homogeneous NAD and NAT nucleation rates and their interpretation as a volume or surface induced effect (see Tabazadeh, 2003, and respective interactive discussion). In recent modelling studies, the surface-based nucleation rates suggested by Tabazadeh et al. (2002) had to be reduced by significant factors in order to match observations (Irie et al., 2004; Larsen et al., 2004; Höpfner et al., 2006).

In three simulation experiments at the AIDA (Aerosol Interaction and Dynamics in the Atmosphere) facility of Forschungszentrum Karlsruhe we measured nucleation rates for the formation of NAD in nitric acid solution droplets. The experimental methods and results are discussed in a companion paper by Stetzer et al. (2006). Wagner et al. (2005) analysed series of FTIR spectra from these experiments which clearly show $\alpha-\mathrm{NAD}$ as the predominant phase to nucleate and grow at the conditions in the AIDA aerosol chamber. In the present paper we will discuss the activation energy for NAD nucleation which was calculated from the measured nucleation rates. A new parameterisation to calculate the activation energy as function of temperature and the NAD saturation ratio is fitted to our data and compared to various literature data sets of nucleation rates and activation energies for NAD nucleation. The experimental data are also compared to results of a numerical model which includes detailed schemes of thermodynamic and microphysical processes and also considers specific wall boundary conditions of the aerosol chamber experiments. The process model study allows direct comparison of our parameterisation for activation energies of NAD nucleation with the linear approximations suggested by Salcedo et al. (2001) and Tabazadeh et al. (2002).

\section{Experimental results}

Methods and results of NAD nucleation rate measurements in the AIDA aerosol chamber are discussed in detail in a companion paper by Stetzer et al. (2006) and are briefly summarized here. The basic experimental approach was 
Table 1. Parameters of AIDA experiments and measured nucleation rates $J$ of $\alpha$ NAD. ( $T_{g}$ : Gas temperature; $p_{g}$ : total gas pressure; $f_{w, \mathrm{NA}}$, $X_{\mathrm{NA}}$ : weight and molar fraction of nitric acid in nucleating droplets; $S_{\mathrm{NAD}}$ : saturation ratio with respect to nitric acid dihydrate; $J_{v}, J_{s}$ : volume and surface based nucleation rates; $\Delta G_{\text {act, } \mathrm{v}}$ : activation energy ).

\begin{tabular}{lcccccc}
\hline Experiment & \multicolumn{2}{c}{ E1 } & \multicolumn{2}{c}{ E2 } & \multicolumn{2}{c}{ E3 } \\
\hline Time $(\mathrm{h})$ & 2.4 & 2.8 & 3.0 & 3.5 & 2.3 & 2.5 \\
$T_{g}(\mathrm{~K})$ & 192.2 & 192.1 & 197.1 & 197.0 & 195.8 & 195.8 \\
$p_{g}(\mathrm{hPa})$ & 164.5 & 163.5 & 174.1 & 172.9 & 180.0 & 180.0 \\
$f_{w, \mathrm{NA}}$ & 0.569 & 0.577 & 0.550 & 0.560 & 0.564 & 0.565 \\
$X_{\mathrm{NA}}$ & 0.274 & 0.280 & 0.259 & 0.266 & 0.269 & 0.271 \\
$S_{\mathrm{NAD}}$ & 9.67 & 10.2 & 6.59 & 7.06 & 7.71 & 7.80 \\
$J_{v}\left(\mathrm{~cm}^{-3} \mathrm{~s}^{-1}\right)$ & $4.1 \times 10^{6}$ & $1.9 \times 10^{7}$ & $<4.4 \times 10^{4}$ & $<5.6 \times 10^{4}$ & $3.9 \times 10^{5}$ & $6.0 \times 10^{5}$ \\
$\Delta G_{\mathrm{act}, \mathrm{v}}\left(\mathrm{kcal} \mathrm{mol}^{-1}\right)$ & 24.62 & 24.02 & $>27.03$ & $>26.93$ & 26.01 & 25.84 \\
$J_{s}\left(\mathrm{~cm}^{-2} \mathrm{~s}^{-1}\right)$ & 21.8 & 101.6 & $<0.3$ & $<0.4$ & 2.4 & 3.7 \\
\hline
\end{tabular}

to observe homogeneous nucleation of solid hydrates in an aerosol cloud of supercooled, micrometer-sized $\mathrm{HNO}_{3} / \mathrm{H}_{2} \mathrm{O}$ solution droplets over a time period of several hours. Care was taken to simulate as closely as possible thermodynamic conditions prevailing in PSCs. Prior to each experiment, the large aerosol vessel was evacuated and replenished with particle free synthetic air to a pressure between 160 and $180 \mathrm{hPa}$. Binary $\mathrm{HNO}_{3} / \mathrm{H}_{2} \mathrm{O}$ particles added to the well-mixed volume $\left(84 \mathrm{~m}^{3}\right)$ of the chamber at the beginning of an experiment, reached a composition in equilibrium with the surrounding gas-phase within a few minutes. While part of the gas-phase water and nitric acid was steadily deposited to the cold chamber walls made of aluminium, the slowly evaporating liquid aerosol particles served as a reservoir to maintain, over a time period of up to $5 \mathrm{~h}$, a nitric acid concentration close to the saturation pressure with respect to the liquid aerosol. Because water and nitric acid are deposited to the wall at different rates, the relative humidity steadily decreased and therefore the nitric acid concentration in the binary solution droplets increased during the course of an experiment. Consequently, the nitric acid vapour pressure and the saturation ratio with respect to the solid nitric acid hydrates also increased. The saturation ratios ranged between 3 and 10 with respect to nitric acid dihydrate (NAD) and between 18 and 26 with respect to nitric acid trihydrate (NAT). These values are at least partly overlapping with the stratospheric range of NAD and NAT saturation ratios.

Three simulation experiments (E1, E2, E3) were carried out at gas temperatures $T_{g}$ between 192.1 and $197.1 \mathrm{~K}$ and pressures $p_{g}$ between $163.5 \mathrm{hPa}$ and $180.0 \mathrm{hPa}$ (see Table 1). During each experiment, the volume and surface nucleation rates of NAD particles, $J_{v}$ and $J_{s}$, were calculated from the increase rate of the NAD particle number concentration and the respective aerosol volume and surface concentrations (see Stetzer et al., 2006, for details). Only lower limits where obtained during experiment E2. The NAD particles were detected with an optical particle counter (OPC). Because of the very low formation rates we had to average the OPC data over time periods of about $15 \mathrm{~min}$ in order to minimize counting errors. Therefore we obtained only two nucleation rate data points for each experiment. For E1 and E2 nitric acid mass concentrations and weight fractions of the liquid aerosol given in Table 1 were retrieved from in situ FTIR extinction spectra as described by Wagner et al. (2003). For E3, no reliable FTIR data was obtained during the nucleation of NAD particles. The composition of the liquid particles was therefore calculated with the aerosol inorganics model AIM (Carslaw et al., 1995; Clegg et al., 1998) which is available via the world wide web (http://mae.ucdavis.edu/wexler/aim), using the measured $T_{g}$ and relative humidity as input parameters. Assuming saturated gas-phase conditions with respect to the liquid phase, the NAD saturation ratio $S_{\mathrm{NAD}}$ was calculated with the same model.

As mentioned above, the number concentration of solid NAD particles formed by homogeneous nucleation of the binary solution droplets was measured with an optical particle counter. The solid hydrate particles could be distinguished from the small solution droplets because they grew to larger sizes by nitric acid vapour diffusion from the evaporating liquid particles to the solid-phase particles. Two thermodynamically metastable phases of nitric acid dihydrate, $\alpha$ $\mathrm{NAD}$ and $\beta$-NAD, were identified in previous studies (Tizek et al., 2002). The formation of the less stable phase $\alpha$-NAD is favoured because of the lower activation barrier, according to Ostwald's step rule. During E1, the analysis of FTIR spectra clearly revealed $\alpha$-NAD as the dominant phase nucleating in our experiments (Stetzer et al., 2006). A detailed analysis of the same spectra by Wagner et al. (2005) showed that the 
shape of the NAD particles which grew by vapour deposition over a time period of about one hour may be approximated by oblate spheroids with aspect ratios larger than 5 .

In a companion paper, Stetzer et al. (2006) discuss the AIDA results in comparison with literature data sets assuming the critical germ to form either in the volume or near the surface of the supercooled liquid particles. The latter was suggested by Tabazadeh et al. (2002) who argued that better agreement between the different data sets was achieved by describing the nucleation as a surface-induced effect. Table 1 lists the NAD volume nucleation rates $J_{v}$ which were determined from the AIDA experiments. For E2 only upper limits of the nucleation rates were obtained because only a small number of solid particles were formed during this experiment. It can be seen from the data listed in Table 1 that in the AIDA experiments NAD nucleation rates were measured for binary $\mathrm{HNO}_{3} / \mathrm{H}_{2} \mathrm{O}$ droplets with nitric acid molar fraction between 0.26 and 0.28 at $192 \mathrm{~K}<T_{g}<197 \mathrm{~K}$ and $7<S_{\mathrm{NAD}}<10$. The estimated uncertainties are $\pm 70 \%$ for the nucleation rates and $\pm 10 \%$ for $S_{\mathrm{NAD}}$. The resulting uncertainty range for the activation energy $\Delta G_{\text {act, } v}$ is +0.5 to $-0.3 \mathrm{kcal} \mathrm{mol}^{-1}$. The activation enregy will be discussed in the following sections.

\section{Evaluation of nucleation rate data and activation en- ergies}

According to classical nucleation theory, the rate $J_{v}$ at which stable solid nuclei form in a supercooled fluid per unit time and unit volume as function of the temperature $T$ can be calculated as

$J_{v}(T)=n_{\text {liq }} \frac{k T}{h} \exp \left[\frac{-\Delta G_{\text {act }, \mathrm{v}}(T)}{R T}\right]$,

where $n_{\text {liq }}$ is the number density of the nucleating species in the fluid (in our case the number density of $\mathrm{NO}_{3}^{-}$in the aqueous phase), $k, h$, and $R$ are the Boltzmann constant, Planck constant, and universal gas constant, respectively, and $\Delta G_{\text {act, }, \mathrm{v}}$ is the nucleation activation energy related to the formation and growth of stable nuclei in the fluid volume. Equation (1) can be solved for

$\Delta G_{\text {act, }}(T)=R T \ln \left[\frac{k T}{h} \frac{n_{\text {liq }}}{J_{v}(T)}\right]$

to calculate the activation energy from measured nucleation rates.

The filled circles in Fig. 1 show $\Delta G_{\text {act,v }}$ for the nucleation of NAD in $\mathrm{HNO}_{3} / \mathrm{H}_{2} \mathrm{O}$ solution droplets measured in AIDA experiments (see Table 1). The literature data sets also shown in Fig. 1 are taken from the nucleation rate measurements of (1) small droplets in an aerosol settling chamber (Disselkamp et al., 1996; Prenni et al., 1998) and an aerosol flow tube system (Bertram and Sloan, 1998a; Bertram et al., 2000), both with FITR detection for the transition from the liquid to the solid phase, and of (2) larger droplets deposited on cooled substrates with freezing detection by optical microscopy (Salcedo et al., 2000, 2001) and Raman microscopy (Knopf et al., 2002). $\Delta G_{\text {act,v }}$ is plotted as function of the NAD saturation ratios, $S_{\mathrm{NAD}}$, which were, if not explicitly mentioned in the respective literature, calculated from the known composition of the nitric acid solutions and the temperature using the AIM thermodynamic model (Carslaw et al., 1995; Clegg et al., 1998).

The dashed line in Fig. 1 indicates the linear fit suggested by Salcedo et al. (2001) to approximate the NAD activation energy, and thereby the nucleation rates, as function of $S_{\mathrm{NAD}}$. This fit is based on their own data and the data by Bertram and Sloan (1998a) which was measured at $10<S_{\mathrm{NAD}}<33$. Salcedo et al. (2001) noted that the linear relationship should not be extrapolated and applied to $S_{\mathrm{NAD}}$ beyond the range of their experimental data. In the same work Salcedo et al. (2001) suggest another linear fit for the activation energy of NAT nucleation as function of the NAT saturation ratio in the range $50<S_{\mathrm{NAT}}<110$ which relies on their own data set and measurements of NAT nucleation in a flow tube cooled to temperatures below 167.2 K (Bertram and Sloan, 1998b). The earlier settling chamber measurements (Disselkamp et al., 1996; Prenni et al., 1998) have been disregarded by Salcedo et al. (2001). As already mentioned in the introduction, Tabazadeh et al. (2002) argued that better agreement between all available data sets on NAD nucleation is achieved assuming surface instead of volume induced crystallisation of the solid hydrate. From this assumption linear relationships for the activation energy of NAT and NAD surface nucleation were derived as function of temperature and the nitric acid molar fraction in the supercooled liquid particles.

However, a problem of applying these linear relations to calculate NAD and NAT nucleation rates in stratospheric models arises from the fact that in regions of polar stratospheric cloud formation NAD saturations are typically less than about 8 and NAT saturations are less than about 30. This is well below the range of saturation ratios achieved so far in laboratory experiments. Linear extrapolations of $\Delta G_{\text {act }}$ to stratospheric saturation ratios are physically unreasonable as the activation energy should approach infinity, corresponding to a zero nucleation rate if the saturation ratio approaches one. As already discussed by Knopf et al. (2002), this linear extrapolation may lead to unrealistically high nucleation rates. In Sect. 5 we will discuss in detail how our experimental data sets compare to the results of a process model which makes use of the linear equations by Salcedo et al. (2001) and Tabazadeh et al. (2002) to calculate the NAD formation rate as function of the thermodynamic properties of the liquid aerosol particles. The process model will be described in Sect. 4.

The increasing slope of $\Delta G_{\text {act,v }}$ with decreasing $S_{\mathrm{NAD}}$ is obvious from the laboratory data summarized in Fig. 1. The AIDA data for instance show for $S_{\mathrm{NAD}}<10$ a much steeper 


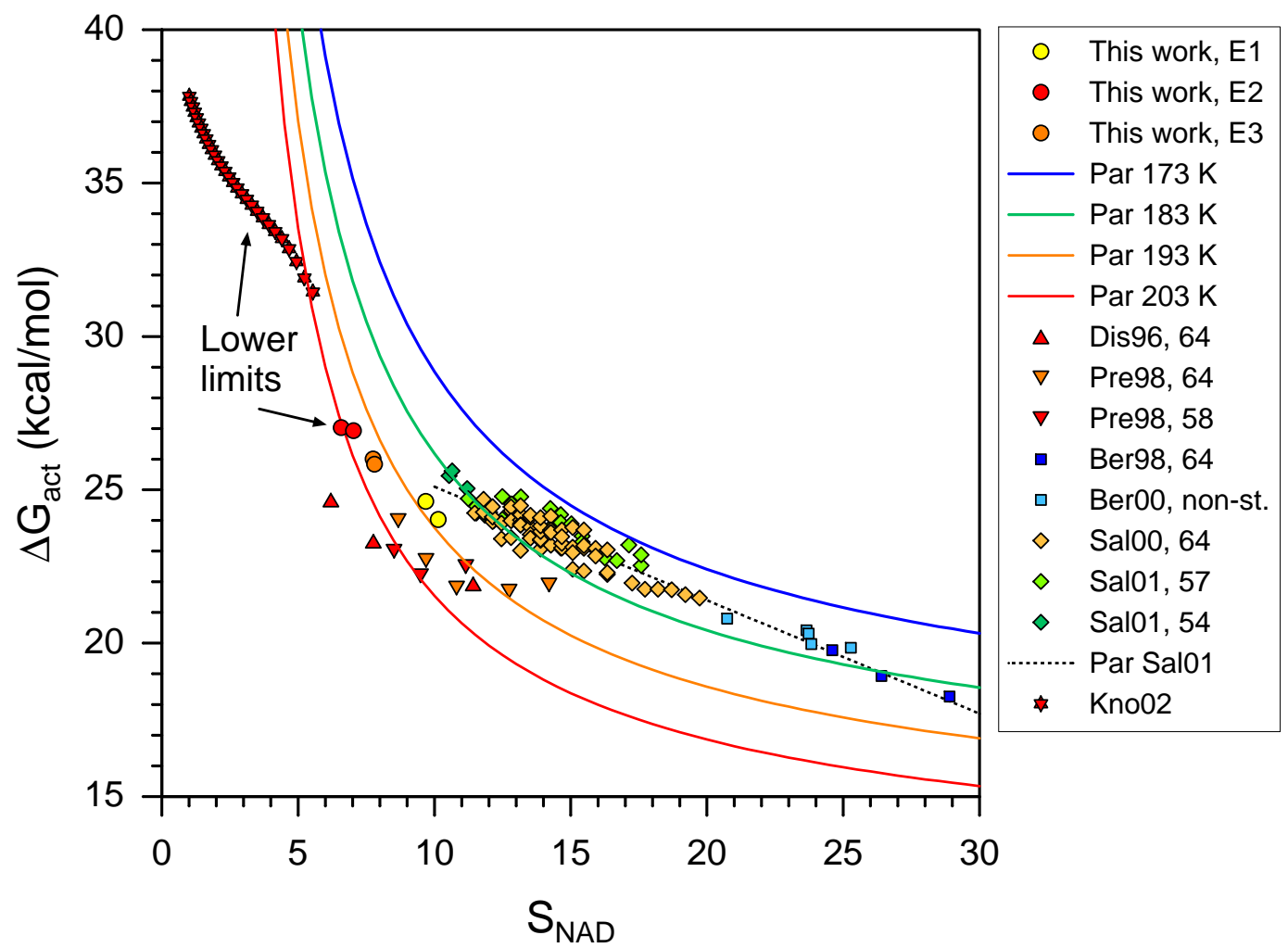

Fig. 1. Activation energies for the homogeneous nucleation of NAD calculated from laboratory nucleation rate data using Eq. (2). Data from the present work are compared to literature data measured for binary $\mathrm{HNO}_{3} / \mathrm{H}_{2} \mathrm{O}$ solution droplets of different nitric acid weight fraction by Disselkamp et al. (1996) (Dis96, 64 wt.\%), Prenni et al. (1998) (Pre98, 64 wt.\% and 58 wt.\%), Bertram and Sloan (1998a) (Ber98, 64 wt.\%), Bertram et al. (2000) (Ber00, non-stoichiometric aerosol composition), Salcedo et al. (2000) (Sal00, 64 wt.\%), Salcedo et al. (2001) (Sal01, $57 \mathrm{wt} . \%$, and 54 wt.\%), and Knopf et al. (2002) (Kno02, only lower limits of $\Delta G_{\mathrm{act}, \mathrm{v}}$ ). The dashed line indicates the interpolation line given by Salcedo et al. (2001).

dependence on $S_{\mathrm{NAD}}$ than the fit suggested by Salcedo et al. (2001) for $10<S_{\mathrm{NAD}}<30$ which is indicated by the dashed line. This steeper slope at $S_{\mathrm{NAD}}<10$ is also indicated by the data from Prenni et al. (1998), which where disregarded in the analysis by Salcedo et al. (2001), and the lower limits from the work by Knopf et al. (2002). Based on our own results and the available literature data which were measured at different temperatures, we suggest a new parameterisation of $\Delta G_{\mathrm{act}, \mathrm{v}}$ as function of $S_{\mathrm{NAD}}$ and the temperature. This parameterisation is based on classical nucleation theory where the nucleation activation energy is given by the sum of the free energy for the formation of the critical germs, $\Delta G_{\text {germ }}$, and the so-called diffusion activation energy $\Delta G_{\mathrm{diff}}$ :

$\Delta G_{\mathrm{act}, \mathrm{v}}=\Delta G_{\mathrm{germ}}+\Delta G_{\mathrm{diff}}$.

The latter accounts for the fact that, in our case, nitric acid molecules need to diffuse across the boundary between the supercooled solution and the solid NAD germ. The first term can be expressed as function of $S_{\mathrm{NAD}}, T$, the interfacial tension $\sigma_{s l}$ between the solid and liquid phase, and the molar volume $v_{s}$ of the growing NAD germs:

$\Delta G_{\text {germ }}=\frac{16}{3} \pi \sigma_{s l}^{3}\left[\frac{v_{s}}{R T \ln S_{\mathrm{NAD}}}\right]^{2}$.

Equations (3) and (4) can be simplified to

$\Delta G_{\mathrm{act}, \mathrm{par}}=A\left[\frac{1}{T \ln S_{\mathrm{NAD}}}\right]^{2}+B$

which was used to fit the laboratory data shown in Fig. 1. The solid lines in Fig. 1 show results of Eq. (5) calculated for temperatures between 173 and $203 \mathrm{~K}$ with

$A=\frac{16}{3} \pi \sigma_{s l}^{3}\left[\frac{v_{s}}{R}\right]^{2}=2.5 \times 10^{6} \frac{\mathrm{kcalK}^{2}}{\mathrm{~mol}}$

and

$B(T)=\Delta G_{\text {diff }}=(11.2-0.1(T-192)) \frac{\mathrm{kcal}}{\mathrm{mol}}$

with the temperature given in $\mathrm{K}$.

Tisdale et al. (1997) have interpolated own measurements of the diffusion activation energy for NAD crystallisation at 


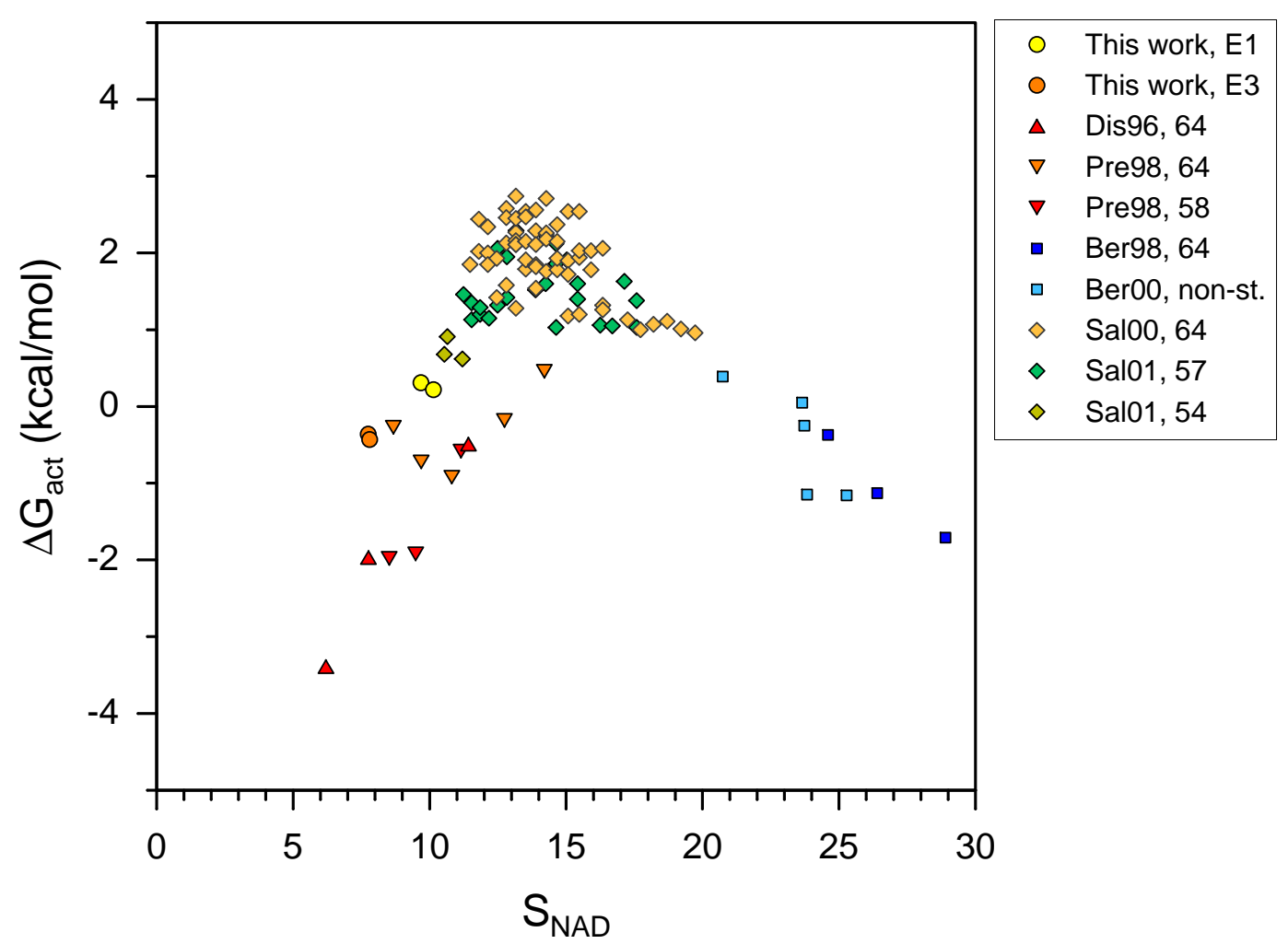

Fig. 2. Difference between the measured activation energies shown Fig. 1 and respective activation energies calculated with Eqs. (5) to (7).

temperatures below $180 \mathrm{~K}$ to data from viscosity measurements at temperatures above $180 \mathrm{~K}$. This fit shows the diffusion activation energy to increase from about $9.6 \mathrm{kcal} \mathrm{mol}^{-1}$ at $199 \mathrm{~K}$ to about $13 \mathrm{kcal} \mathrm{mol}^{-1}$ at $190 \mathrm{~K}$. Our empirical fit for $\Delta G_{\text {act,v }}$ suggests $\Delta G_{\text {diff }}$ to increase from $10.4 \mathrm{kcal} \mathrm{mol}^{-1}$ to $11.4 \mathrm{kcal} \mathrm{mol}^{-1}$ in the same temperature range. Regarding the difficulties and uncertainties for retrieving such quantities, both results are in good agreement, however, our approach indicates a smaller temperature dependence of the diffusion activation energy.

The interfacial tension $\sigma_{s l}$ between the solid NAD and the liquid phase, especially its temperature dependence, is only poorly understood. We have therefore, as a first order estimate, assumed the parameter $A$ in Eq. (5) to be constant. This implies a constant interfacial tension of $51 \mathrm{kcal} \mathrm{mol}^{-1} \mathrm{~cm}^{-2}$ which was calculated from Eq. (6) with a molar volume of $66 \mathrm{~cm}^{3} \mathrm{~mol}^{-1}$ for the NAD germ. This value is about twice as large as the interfacial tension of about $25 \mathrm{kcal} \mathrm{mol}^{-1} \mathrm{~cm}^{-2}$ derived by Prenni et al. (1998) but compares well to a value of $44.5 \mathrm{kcal} \mathrm{mol}^{-1} \mathrm{~cm}^{-2}$ derived from the so-called Turnbull expression at $200 \mathrm{~K}$ (Turnbull, 1950).

The activation energy curves in Fig. 1 comprise all laboratory data sets which have been measured in the same temperature range. Figure 2 shows the difference between the measured activation energies and $\Delta G_{\text {act,par }}$ calculated for the temperature of any data point. It can be seen that the pa- rameterisation agrees within $\pm 0.5 \mathrm{kcal} \mathrm{mol}^{-1}$ to the $\Delta G_{\text {act,v }}$ measured in our experiments. Agreement within about $\pm 1.0 \mathrm{kcal} \mathrm{mol}^{-1}$ is achieved to the data sets for $64 \mathrm{wt} . \% \mathrm{ni}-$ tric acid solutions by Prenni et al. (1998), most of the data by Bertram and Sloan (1998a) and Bertram et al. (2000), and the data sets for $54 \mathrm{wt} . \%$ nitric acid solutions by Salcedo et al. (2001). All other data sets by Salcedo et al. (2001) show activation energies more than $1 \mathrm{kcal} \mathrm{mol}^{-1}$ above $\Delta G_{\text {act,par. }}$. Especially the low $S_{\mathrm{NAD}}$ data from Prenni et al. (1998) and Disselkamp et al. (1996) are about $2 \mathrm{kcal} \mathrm{mol}^{-1}$ below $\Delta G_{\text {act, par }}$. A change of $1 \mathrm{kcal} \mathrm{mol}^{-1}$ corresponds to a change in the nucleation rate by about one order of magnitude (see Eq. 1). Therefore we conclude that most of the literature data for NAD nucleation rates agrees within about two orders of magnitude with the parameterisation suggested in Eqs. (5) to (7). Part of the measurements by Salcedo et al. (2001) deviate by more than two orders of magnitude.

\section{Model description}

The analysis of phase changes in supercooled solution droplets requires a detailed description of the droplets themselves which, in the case of the present studies, are subjected to varying temperature, pressure, and partial pressure of the condensable trace gases. Based on equations describing the growth kinetics of particles depending on the saturation 
levels of the condensing (or evaporating) trace gases, a model was developed to calculate the time-dependent size and composition of the particles. Since the mass growth rate is proportional to the difference between the partial pressure of the condensing gas and the vapour pressure over the particle surface, the necessary vapour pressures have to be known as a function of particle composition and temperature. The model uses the parameterisation given by Luo et al. (1995) which correlates the vapour pressures of $\mathrm{H}_{2} \mathrm{O}, \mathrm{HNO}_{3}, \mathrm{HCl}$, and $\mathrm{HBr}$ to the mass fractions of these compounds and of $\mathrm{H}_{2} \mathrm{SO}_{4}$ in the particles. In the present study only $\mathrm{H}_{2} \mathrm{O}$ and $\mathrm{HNO}_{3}$ had to be considered as constituents. The kinetic prefactor of the growth equation includes dependencies on the particle diameter, gas pressure, diffusivity of the condensing gas, and the accommodation coefficient (assumed to be unity in our calculations). Details of the model were already discussed by Bunz and Dlugi (1991).

The important partial pressures of the condensable gases are calculated on the basis of a detailed balancing taking into account the initial conditions, wall deposition, and condensation to or evaporation from the particles. In the present study the process model application mainly aimed at comparing the different formulations for NAD nucleation to the measured formation rates. These formation rates critically depend on the temperature and the composition of the liquid aerosol to nucleate. To minimize systematic uncertainties, the model was enforced to follow the measured time profiles of pressure, temperature, as well as the nitric acid mass concentration and mass fraction of the liquid aerosol particles retrieved from the FTIR spectra. For E3 FTIR measurements were available only during the first $15 \mathrm{~min}$ after the aerosol addition was finished. For this experiment the model used the relative humidity to calculate the composition of the liquid aerosol particles. The relative humidity was calculated form the water vapour pressure measured with the TDL spectrometer and the water saturation pressure with respect to the gas temperature.

Constraining the model to the measured data sets evaded uncertainties concerning the wall deposition rates of the trace gases. Therefore, the composition of the particles is known at any time of the calculation and the activities of the different components (water and nitric acid in our case) can be calculated on the basis of the composition dependent vapour pressures for the particle phase. It should be mentioned that uncertainties exist concerning the vapour pressures of $\mathrm{H}_{2} \mathrm{O}$ and $\mathrm{HNO}_{3}$ over solutions at low temperatures and that results of the different models (Luo et al., 1995; Carslaw et al., 1995; Clegg et al., 1998) differ by up to $20 \%$. The NAD and NAT saturation ratios calculated from these data may be uncertain by the same amount.

The activities in the particle phase are the basis for the calculation of the nucleation rates. The probability for the phase transition of a specific droplet is proportional to the so-called nucleation rate $J$ times either the volume or the surface of the droplet depending on the formulation of $J$ as a volume- based rate $J_{v}$ (in units $\mathrm{cm}^{-3} \mathrm{~s}^{-1}$ ) or a surface-based rate $J_{S}$ (in units $\mathrm{cm}^{-2} \mathrm{~s}^{-1}$ ), respectively. In both cases the nucleation rate is determined by the exponent of the activation energy times a kinetic pre-factor (see Eq. 1 for the volume rate). These terms can either be determined by theoretical considerations or by evaluation of laboratory experiments. For calculating the formation rate of NAD particles in the model, three different formulations for the activation energy of NAD nucleation have been implemented, namely (1) the linear fit of $\Delta G_{\mathrm{act}, \mathrm{v}}$ as function of the NAD saturation ratio $S_{\text {NAD }}$ (Salcedo et al., 2001), hereafter termed model run Sal01, (2) the linear expression for calculating the activation energy of the surface-induced NAD nucleation as function of the temperature and liquid particle composition (Tabazadeh et al., 2002), hereafter termed model run Tab02, and (3) the new parameterisation for calculating $\Delta G_{\mathrm{act}, \mathrm{v}}$ as function of temperature and $S_{\mathrm{NAD}}$ (Eqs. 5 to 7 ), hereafter termed model run Moe06.

At the beginning of the three experiments the NAD saturation ratio and nitric acid mass fraction passed through values slightly below the minimum values of previous laboratory studies (see Stetzer et al., 2006, and discussion in Sect. 5). As discussed above, linear equations for activation energies and especially extrapolations to lower saturation ratios or more dilute solution particles are unreasonable from a theoretical point of view. Nevertheless, in lack of other concepts and for comparison with our new parameterisation, we rigorously applied, for the model runs Sal01 and Tab02, the linear equations to the whole range of thermodynamic conditions and particle compositions of our simulation experiments. This gives at least an estimate of how these formulations apply to the conditions of our experiments which, in contrast to previous laboratory studies, more closely simulate PSC conditions. Another motivation for this approach was to directly apply and test, for small nitric acid solution droplets, the concept of surface-induced NAD nucleation in comparison to the volume nucleation rate. Comparisons between the model and experimental results are presented in the following sections.

\section{Model results}

Figures 3, 4, and 5 show model results together with experimental data for experiments E1, E2, and E3, respectively. The time is given in hours relative to a reference time for each experiment which is defined as the start time of adding binary nitric acid solution droplets to the aerosol vessel. Panel (a) shows the saturation ratios of the solid phases NAT, NAD, and ice which were calculated with the model assuming saturated conditions between the gas phase and the supercooled liquid aerosol droplets. It can be seen that in all three experiments the aerosol was subsaturated with respect to the ice phase but highly supersaturated with respect to the nitric acid hydrates. The horizontal lines in panels (a) indicate the lower limits of the range of saturation ratios which was covered by 


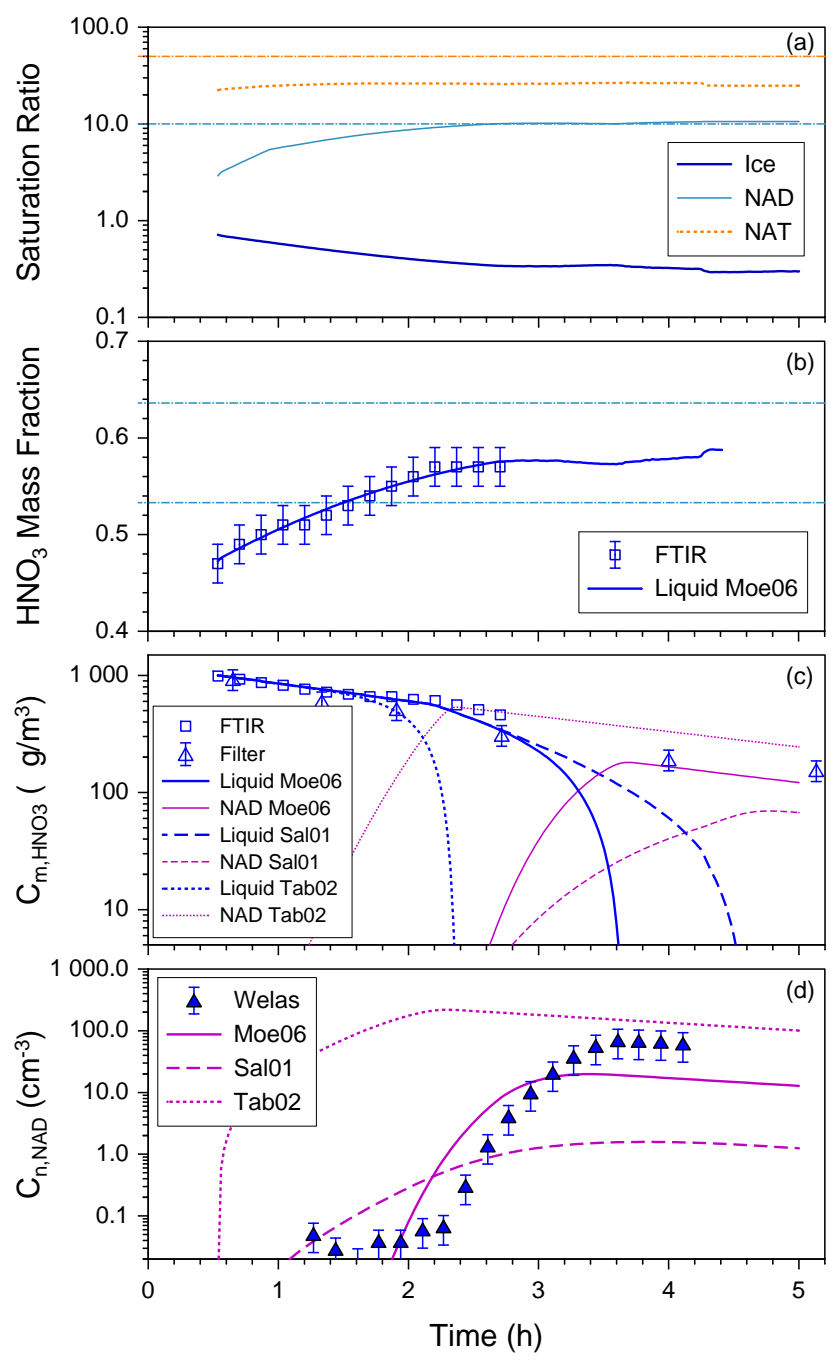

Fig. 3. Comparison of experimental and modelling data for experiment E1. Panel (a): Saturation ratio with respect to ice, NAD, and NAT, calculated assuming saturated conditions with respect to the supercooled liquid phase. The horizontal lines indicates the range to which Salcedo et al. (2001) suggested a linear fit of the activa-

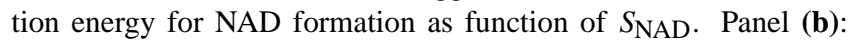
Nitric acid weight fraction of liquid aerosol retrieved from FTIR extinction spectra. The horizontal lines indicate the range to which Tabazadeh et al. (2002) suggested a linear fit of volume-based NAD nucleation rates as function of the temperature and molar composition. Panel (c): Nitric acid mass concentration from filter analysis (total $\mathrm{HNO}_{3}$ ), FTIR analysis (only liquid aerosol fraction) and model runs (liquid aerosol and NAD). Panel (d): NAD number concentrations from optical particle counter Welas and model runs Moe06 (solid), Sal01 (dashed), and Tab02 (dotted).

the data sets used for the evaluation of NAD and NAT activation energies by Salcedo et al. (2001). Only during E1, $S_{\mathrm{NAD}}$ exceeded a value of 10 which is the lower limit for the NAD case. During E2 and E3 the maximum $S_{\mathrm{NAD}}$ was about 7 and 8 , respectively.
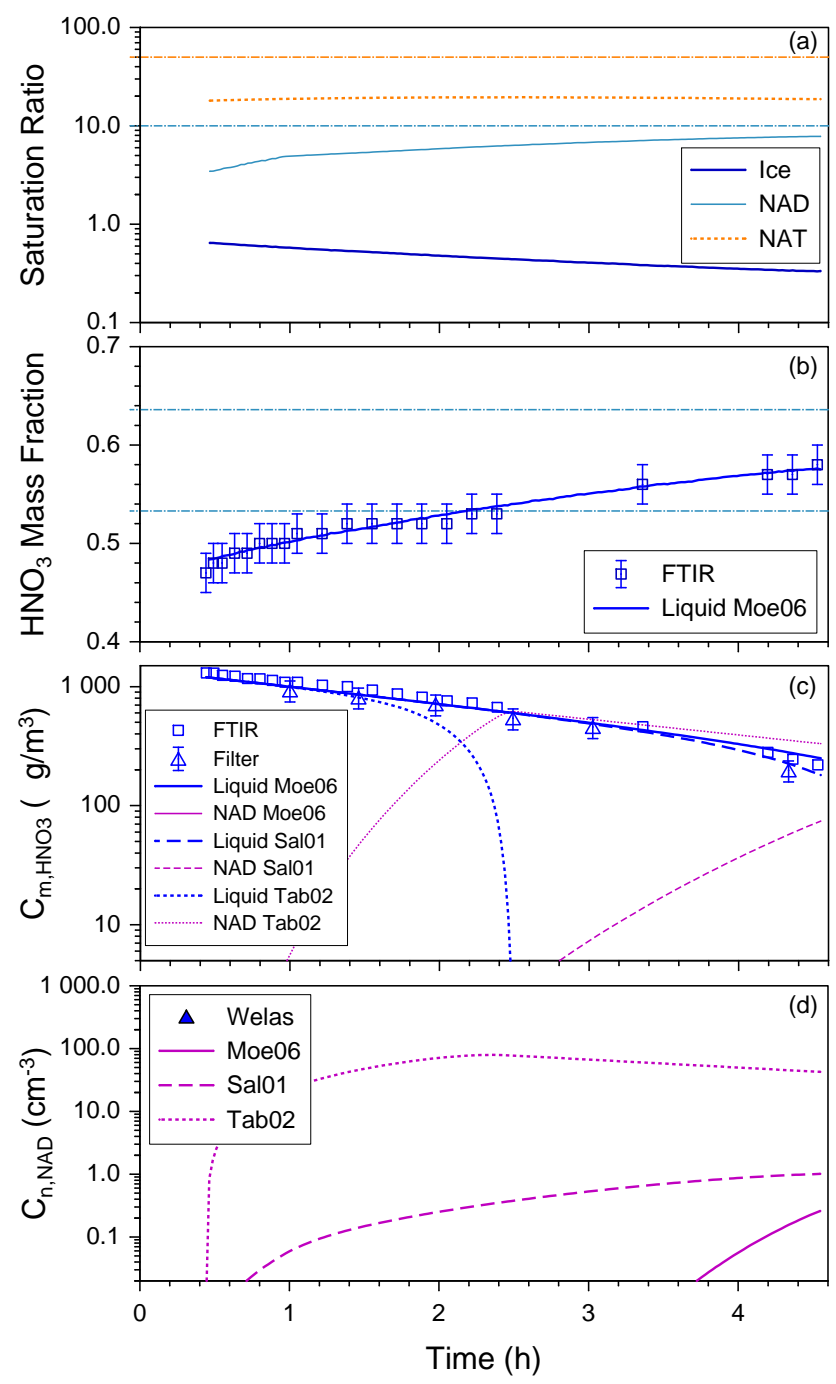

Fig. 4. Same as Fig. 3 for experiment E2.

While the relative humidity decreases with time, the NAD and NAT saturation ratios increase which is mainly due to wall deposition of water and nitric acid at different rates. Because the binary liquid particles are almost in equilibrium with the ambient conditions, the nitric acid mass fraction in the liquid droplets (panel b) also increases with time from about 0.45 at the beginning of the experiment to about 0.57 when NAD nucleation was observed. This corresponds to an increase of the nitric acid molar fraction from 0.189 to 0.274 and a decrease of the water to nitric acid molar ratio from 4.3 to 2.65. The empirical linear fit of activation energies for the surface induced nucleation of NAD by Tabazadeh et al. (2002) relies on data sets with nitric acid molar fractions of the liquid aerosol from 0.246 to 0.333 which corresponds to nitric acid weight fractions between 0.533 and 0.636 . These values are indicated in panel (b) as horizontal dashed lines. 
Panels (c) of Figs. 3 to 5 show the modelled evolution of the nitric acid mass concentration in the binary liquid (blue lines) and the NAD phases (pink lines). The results for the model runs Tab02, Sal01, and Moe06 are plotted as dotted, dashed, and solid lines, respectively. Nitric acid mass concentrations from FTIR extinction spectra (squares) and ionchromatographic analysis of nylon filter samples (triangles) are also shown (see Stetzer et al., 2006, for a discussion of the measured data). A comparison of modelled and measured number concentration of NAD particles is depicted in panels (d). It can clearly be seen, both from panels (c) and (d), that the model results are significantly different for the different parameterisations (see Sect. 4).

With the assumption of surface induced nucleation by Tabazadeh et al. (2002) NAD particles emerge by far too early compared to the observations. Furthermore, this formulation predicts NAD particle concentrations which are orders of magnitude larger than the ones measured, especially for experiments E2 and E3. Note that during E2 only few NAD particles were detected. From the detection limit of the optical particle counter we derive an upper limit of $0.1 \mathrm{~cm}^{-3}$ for the NAD number concentration. The model runs Sal01 also tend to overestimate the nucleation rates at lower $S_{\mathrm{NAD}}$ which also results in early NAD formation. This is an artefact of the linear extrapolation to $S_{\mathrm{NAD}}<10$ especially during E2 and E3. Only the model runs Moe06 which use the formulation of NAD nucleation discussed in Sect. 3 are in good agreement with the experimental results for all experiments $\mathrm{E} 1, \mathrm{E} 2$, and E3.

\section{Volume versus surface induced NAD nucleation}

Recently, there was some debate in the literature whether homogeneous nucleation in supercoooled nitric acid solutions is initiated on the surface or in the overall volume of small nitric acid droplets in the atmosphere (Knopf et al., 2002; Tabazadeh et al., 2002; Tabazadeh, 2003). Tabazadeh (2003) argued that nucleation measurements in large droplets like those by Knopf et al. (2002) are not sensitive to the surface-induced nucleation which may dominate in micronsized droplets with a large surface-to-volume ratio. We have measured nucleation rates of NAD formation of supercooled nitric acid solution droplets with diameters less than $1 \mu \mathrm{m}$. The comparison of experimental and process model results (see Figs. 3 to 5) clearly shows that the linear fit of the activation energy for surface induced NAD nucleation as function of temperature and nitric acid molar fraction suggested by Tabazadeh et al. (2002) disagrees to our results. This is also supported by Fig. 6 which shows the size distributions of liquid and NAD particles measured with an optical particle counter (upper panel) and calculated in the model runs Moe06 (panel 2), Sal01 (panel 3), and Tab02 (panel 4). The size distributions are depicted as coloured contour plots with low number concentration in blue and high number concen-

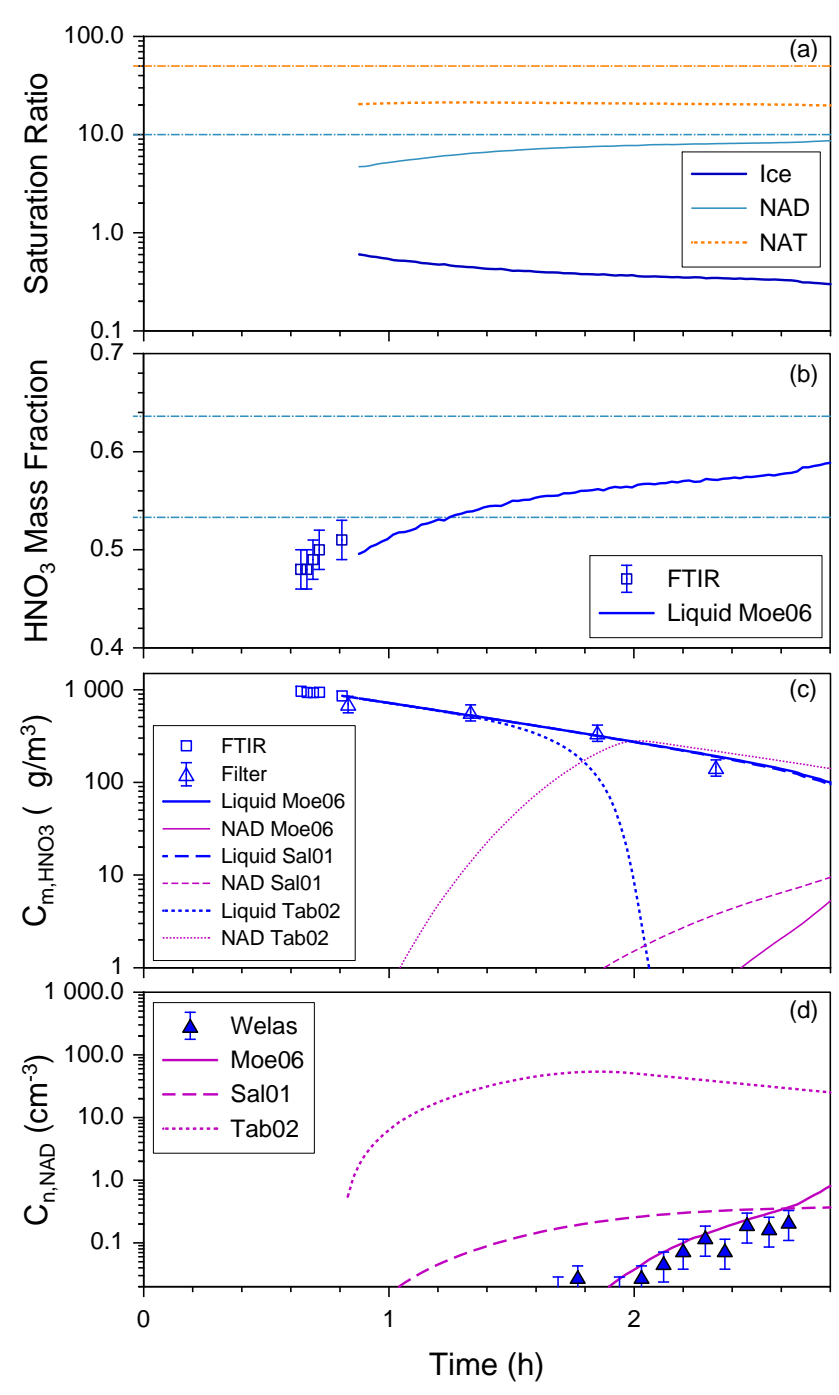

Fig. 5. Same as Fig. 3 for experiment E3.

tration in red. Note the different scales for the colour scheme in the different panels. It can be seen from both the onset time for the formation of larger NAD particles and the complete evaporation of the mode of smaller liquid particles with diameters less than about $1 \mu \mathrm{m}$ that the model run Tab02 clearly overestimates the formation rates of NAD particles. Larsen et al. (2004) also concluded from back-trajectory process model studies of in situ measurements in the Arctic stratosphere in early December 2002 that the parameterisation by Tabazadeh et al. (2002) overestimates the formation rate of solid nitric acid particles.

The model runs Sal01 for E1 to E3 also show early NAD nucleation onset compared to the experimental data. This corresponds to an overestimation of the nucleation rate or an underestimation of the respective activation energy for $S_{\mathrm{NAD}}<10$ which can at least partly be explained by the extrapolation of the linear equation suggested by Salcedo et al. (2001). In microphysical process model studies of the 


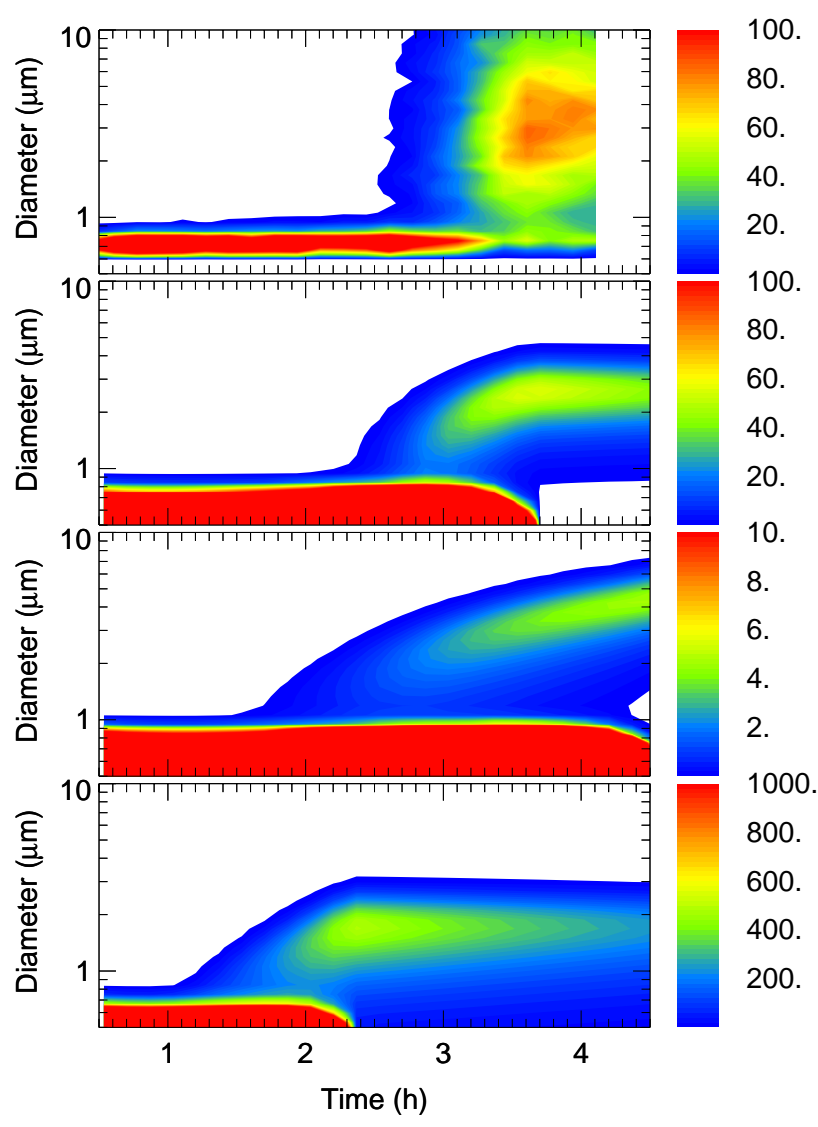

Fig. 6. Time evolution of droplet and NAD particle size distributions $d N / d \log d$ measured with an optical particle counter during experiment E1 (top panel) and obtained from the model runs Moe06 (panel 2), Sal01 (panel 3), and Tab02 (panel 4). The colour code indicates the number concentration of particles (note the different colour scales).

1999-2000 Arctic winter, Drdla and Browell (2004) used a parameterisation of the activation energy for NAD nucleation according to Eqs. (3) and (4) in order to calculate the nucleation rates at synoptic-scale stratospheric PSC conditions. This parameterisation assumed a constant interfacial tension $\sigma_{s l}$ between the solid NAD germ and the supercooled nitric acid solution and a diffusion activation energy of $\Delta G_{\text {diff }}=0$. The interfacial tension was adjusted for the parametrisation used in the model runs to roughly fit the data sets from Salcedo et al. (2001). However, this parameterisation yields activation energies to increase from about 30 to $35 \mathrm{kcal} \mathrm{mol}^{-1}$ at NAD saturations decreasing from 10 to 8 (see Fig. 5 in Drdla and Browell, 2004). These values are by more than $5 \mathrm{kcal} \mathrm{mol}^{-1}$ larger than our experimental data measured in the same range of saturation ratios. From that we conclude that the parameterisation by Drdla and Browell (2004) underestimates the homogeneous nucleation of NAD by at least 5 orders of magnitude for $S_{\mathrm{NAD}}<10$ and should therefore not be used in stratospheric models. Because the formulation for
NAT and NAD nucleation by Drdla and Browell (2004) rely on similar assumptions, the NAT nucleation rates may also be underestimated for NAT saturation ratios below about 50 .

The parameterisation given in Eqs. (5) to (7) also assumes a constant interfacial tension but, in contrast to Drdla and Browell (2004), requires a slightly temperature dependent diffusion activation energy to achieve reasonable agreement to all laboratory data sets of NAD nucleation rates. The fit was empirically adjusted to obtain agreement within less than an order of magnitude to the NAD nucleation rates measured in our simulation experiments (Stetzer et al., 2006) at $192 \mathrm{~K}$ $<T_{g}<197 \mathrm{~K}$ and $7<S_{\mathrm{NAD}}<10$. As discussed in Sect. 3, the same parameterisation agrees within two orders of magnitude with most of the laboratory data of NAD nucleation rates measured at $173 \mathrm{~K}<T_{g}<204 \mathrm{~K}$ and $8<S_{\mathrm{NAD}}<29$. If extrapolated to temperatures and saturation ratios beyond the given ranges, larger deviations may occur e.g. if there is a significant dependence of $\sigma_{s l}$ on temperature at these conditions.

\section{Conclusions}

In this paper we discussed the activation energies $\Delta G_{\text {act }}$ for NAD nucleation in supercooled binary $\mathrm{HNO}_{3} / \mathrm{H}_{2} \mathrm{O}$ solutions droplets of different molar composition and temperature. The activation energies were calculated from nucleation rates measured in AIDA experiments (Stetzer et al., 2006) or taken from the literature (Disselkamp et al., 1996; Prenni et al., 1998; Bertram and Sloan, 1998a; Bertram et al., 2000; Salcedo et al., 2000, 2001; Knopf et al., 2002). A new formulation of the activation energy $\Delta G_{\text {act,par for the }}$ volume-based NAD nucleation as function of temperature and the saturation ratio $S_{\mathrm{NAD}}$ of nitric acid with respect to the solid NAD phase was fitted to the AIDA results. This formulation is also in reasonable agreement with most literature data of $\Delta G_{\mathrm{act}, \mathrm{v}}$. According to classical nucleation theory, this approach accounts for the fact that $\Delta G_{\text {act }}$ should steeply increase for $S_{\mathrm{NAD}}$ approaching 1 . In lack of reliable data for the interface tension $\sigma_{s l}$ between the growing NAD germ and the supercooled solution, we empirically fitted $\Delta G_{\text {act,par }}$ to the laboratory data sets and obtained a mean value $\sigma_{s l}=51 \mathrm{cal} \mathrm{mol}^{-1} \mathrm{~cm}^{-2}$ as the best estimate. Because the interface energy normally decreases with decreasing temperature, this approach tends to overestimate the activation energy and therefore to underestimate the nucleation rate at lower $S_{\mathrm{NAD}}$. A linear temperature dependence of the diffusion activation energy is obtained with $11.4 \mathrm{kcal} \mathrm{mol}^{-1}$ at $190 \mathrm{~K}$ and $10.4 \mathrm{kcal} \mathrm{mol}^{-1}$ at $200 \mathrm{~K}$.

A process model was applied to compare the formulation of NAD nucleation activation energies suggested in the present work to the linear equation for $\Delta G_{\mathrm{act}, \mathrm{v}}$ as function of $S_{\mathrm{NAD}}$ (Salcedo et al., 2001) and the linear fit of $\Delta G_{\mathrm{act}, \mathrm{s}}$ for the surface-induced NAD nucleation as function of the temperature and the nitric acid content of the nucleating solution 
droplets (Tabazadeh et al., 2002). Comparison of the model runs with the experimental results clearly revealed the formulation by Tabazadeh et al. (2002) to overestimate the NAD nucleation rates measured in our experiments at temperatures between 192 and $197 \mathrm{~K}$, NAD saturation ratios between 7 and 10 , and nucleating $\mathrm{HNO}_{3} / \mathrm{H}_{2} \mathrm{O}$ droplets with diameters less than $1 \mu \mathrm{m}$. Disagreement was also observed to the formulation by Salcedo et al. (2001) even for $S_{\mathrm{NAD}}$ close to 10 which was the lower limit for the data considered by Salcedo et al. (2001) for the linear fit to the activation energy as function of $S_{\mathrm{NAD}}$.

The steep dependence of $\Delta G_{\mathrm{act}, \mathrm{v}}$ on $S_{\mathrm{NAD}}$ measured between 7 and 10 could be approximated by the empirical fit suggested in Eqs. (5) to (7) of the present study. This formulation also agrees to the lower limits of $\Delta G_{\mathrm{act}, \mathrm{v}}$ measured by Knopf et al. (2002). Both key parameters for assessing NAD nucleation rates, $S_{\mathrm{NAD}}$ and $T$, are highly variable in the polar winter stratosphere. In a recent paper, NAD and NAT pseudo-heterogeneous nucleation rates where estimated for a stratospheric pressure of $50 \mathrm{hPa}$ and volume mixing ratios of $5 \mathrm{ppm}, 10 \mathrm{ppb}$, and $0.5 \mathrm{ppb}$ for $\mathrm{H}_{2} \mathrm{O}, \mathrm{HNO}_{3}$, and $\mathrm{H}_{2} \mathrm{SO}_{4}$, respectively (Knopf, 2006). At these conditions, the aqueous sulphuric acid particles take up significant amounts of nitric acid at temperatures below about $192 \mathrm{~K}$. Assuming equilibrium composition of the ternary solution particles as a function of the ambient temperature, $S_{\text {NAD }}$ reaches a maximum value of about 4.2 at a temperature of $191 \mathrm{~K}$. For these conditions, the parameterisation given in Eqs. (5) to (7) results in an activation energy of $33.3 \mathrm{kcal} / \mathrm{mol}$ and a respective volume-based nucleation rate of $4 \times 10^{-17} \mathrm{~cm}^{-3} \mathrm{~s}^{-1}$. For a total aerosol volume of $1 \mu \mathrm{m}^{3} \mathrm{~cm}^{-3}$ we obtain a NAD formation rate per unit time and air volume of about $1 \times 10^{-25} \mathrm{~cm}^{-3} \mathrm{~h}^{-1}$. This is by far too low to explain large particles observed in the polar stratosphere with number concentrations in the range $10^{-4} \mathrm{~cm}^{-3}$ to $10^{-3} \mathrm{~cm}^{-3}$ and interpreted as NAD or NAT (Fahey et al., 2001; Brooks et al., 2003; Larsen et al., 2004; Voigt et al., 2005). The formation rates should, as a rough estimate, be larger than $10^{-6} \mathrm{~cm}^{-3} \mathrm{~h}^{-1}$ in order to yield the observed number concentrations within a few days.

The conditions taken for the estimate above are certainly not representative for the entire stratospheric polar vortex. In particular at lower temperatures, pressures, and humidities, $S_{\mathrm{NAD}}$ can be markedly larger than 4 . With the parameterisation suggested in the present paper, NAD formation rates of $10^{-6} \mathrm{~cm}^{-3} \mathrm{~h}^{-1}$ are reached for saturation ratios of about 8 and 9 at temperatures of 190 and $185 \mathrm{~K}$, respectively. From that we conclude, that homogeneous NAD nucleation can only play a role in the formation of polar stratospheric clouds if $S_{\mathrm{NAD}}$ approaches or exceeds these values. The actual values of $S_{\mathrm{NAD}}$ throughout the polar vortex are not easy to assess because they depend on quite uncertain parameters like relative humidity with respect to water, water activities, or saturation pressures at very low temperatures. Furthermore, the actual temperature and composition of the ternary solu- tion droplets need to be known. A thorough assessment of the potential role of homogeneous NAD nucleation for PSC formation on the basis of Eqs. (5) to (7) would require a detailed modelling analysis which is beyond the scope of the present paper.

In a companion paper, Stetzer et al. (2006) discuss the nucleation rate data from the AIDA simulation experiments in more detail and already show that better agreement to most literature data is obtained if the NAD nucleation is formulated as a volume-based rather than a surface-based process. It should be noted that the present work only uses nucleation rate measurements for binary $\mathrm{HNO}_{3} / \mathrm{H}_{2} \mathrm{O}$ solution particles. In case of applying the same formulations to calculate NAD nucleation rates in ternary solution droplets of water, sulphuric acid, and nitric acid which exist in PSCs, it should be kept in mind that the sulphuric acid content may possibly change the NAD nucleation rates. More laboratory studies of NAD and NAT nucleation in STS solution droplets at relevant PSC conditions are certainly needed to provide a more reliable data base for the quantitative formulation of homogeneous nitric acid hydrate formation rates in the polar stratosphere.

Acknowledgements. We thank D. Knopf for helpful discussions and copies of literature data sets. This work was funded by the German Bundesminister für Bildung und Forschung $(\mathrm{BMB}+\mathrm{F})$ through the project "Multiphase processes in the polar stratosphere: in situ measurements and simulations" (POSTA, 07ATF04) which was part of the German Atmospheric Research Programme AFO2000.

Edited by: B. Kärcher

\section{References}

Bertram, A. K. and Sloan, J. J.: Temperature-dependent nucleation rate constants and freezing behavior of submicron nitric acid dihydrate aerosol particles under stratospheric conditions, J. Geophys. Res., 103, 3553-3561, 1998a.

Bertram, A. K. and Sloan, J. J.: The nucleation rate constants and freezing mechanism of nitric acid trihydrate aerosol under stratospheric conditions, J. Geophys. Res., 103, 13 261-13 265, 1998 b.

Bertram, A. K., Dickens, D. B., and Sloan, J. J.: Supercooling of type 1 polar stratospheric clouds: The freezing of submicron nitric acid aerosols having $\mathrm{HNO}_{3}$ mol fractions less than 0.5 , J. Geophys. Res., 105, 9283-9290, 2000.

Brooks, S. D., Baumgardner, D., Gandrud, B., Dye, J. E., Northway, M. J., Fahey, D. W., Bui, T. P., Toon, O. B., and Tolbert, M. A.: Measurements of large stratospheric particles in the Arctic polar vortex, J. Geophys. Res., 108, 4652, doi:10.1029/2002JD003278, 2003.

Bunz, H. and Dlugi, R.: Numerical-Studies on the Behavior of Aerosols in Smog Chambers, J. Aerosol Sci., 22, 441-465, 1991.

Carslaw, K. S., Clegg, S. L., and Brimblecombe, P.: A Thermodynamic Model of the System $\mathrm{HCl}-\mathrm{HNO}_{3}-\mathrm{H}_{2} \mathrm{SO}_{4}-\mathrm{H}_{2} \mathrm{O}$, Including Solubilities of $\mathrm{HBr}$, from $<200$ to $328 \mathrm{~K}$, J. Phys. Chem., 99, 11 557-11574, 1995. 
Carslaw, K. S., Peter, T., Bacmeister, J. T., and Eckermann, S. D.: Widespread solid particle formation by mountain waves in the Arctic stratosphere, J. Geophys. Res., 104, 1827-1836, 1999.

Clegg, S., Brimbleconbe, P., and Wexler, A.: Thermodynamic model of the system $\mathrm{H}^{+}-\mathrm{NH}_{4}^{+}-\mathrm{SO}_{4}^{2-}-\mathrm{NO}_{3}^{-}-\mathrm{H}_{2} \mathrm{O}$ at tropospheric temperatures, J. Phys. Chem. A, 102, 2137-2154, doi:10.1021/jp973042r, 1998.

Curtius, J., Weigel, R., Vössing, H.-J., Wernli, H., Werner, A., Volk, C.-M., Konopka, P., Krebsbach, M., Schiller, C., Roiger, A., Schlager, H., Dreiling, V., and Borrmann, S.: Observations of meteoritic material and implications for aerosol nucleation in the winter Arctic lower stratosphere derived from in situ particle measurements, Atmos. Chem. Phys., 5, 3053-3069, 2005, http://www.atmos-chem-phys.net/5/3053/2005/.

Deshler, T., Larsen, N., Weissner, C., Schreiner, J., Mauersberger, K., Cairo, F., Adriani, A., Di Donfrancesco, G., Ovarlez, J., Ovarlez, H., Blum, U., Fricke, K. H., and Dörnbrack, A.: Large nitric acid particles at the top of an Arctic stratospheric cloud, J. Geophys. Res., 108, 4517, doi:10.1029/2003JD003479, 2003.

Disselkamp, R. S., Anthony, S. E., Prenni, A. J., Onasch, T. B., and Tolbert, M. A.: Crystallization kinetics of nitric acid dihydrate aerosols, J. Phys. Chem., 100, 9127-9137, 1996.

Drdla, K. and Browell, E. V.: Microphysical modeling of the 1999-2000 Arctic winter: 3. Impact of homogeneous freezing on polar stratospheric clouds, J. Geophys. Res., 109, doi:10.1029/2003JD004352, 2004.

Fahey, D. W., Gao, R. S., Carslaw, K. S., Kettleborough, J., Popp, P. J., Northway, M. J., Holecek, J. C., Ciciora, S. C., McLaughlin, R. J., Thompson, T. L., Winkler, R. H., Baumgardner, D. G., Gandrud, B., Wennberg, P. O., Dhaniyala, S., McKinney, K., Peter, T., Salawitch, R. J., Bui, T. P., Elkins, J. W., Webster, C. R., Atlas, E. L., Jost, H., Wilson, J. C., Herman, R. L., Kleinböhl, A., and von König, M.: The detection of large $\mathrm{HNO}_{3}$-containing particles in the winter arctic stratosphere, Science, 291, 10261031, 2001.

Höpfner, M., Larsen, N., Spang, R., Luo, B. P., Ma, J., Svendsen, S. H., Eckermann, S. D., Knudsen, B., Massoli, P., Cairo, F., Stiller, G., Von Clarmann, T., and Fischer, H.: MIPAS detects Antarctic stratospheric belt of NAT PSCs caused by mountain waves, Atmos. Chem. Phys., 6, 1221-1230, 2006, http://www.atmos-chem-phys.net/6/1221/2006/.

Irie, H. and Kondo, Y.: Evidence for the nucleation of polar stratospheric clouds inside liquid particles, Geophys. Res. Lett., 30, 38-1, doi:10.1029/2002GL016493, 2003.

Irie, H., Pagan, K. L., Tabazadeh, A., Legg, M. J., and Sugita, T.: Investigation of polar stratospheric cloud solid particle formation mechanisms using ILAS and AVHRR observations in the Arctic, Geophys. Res. Lett., 31, L15107, doi:10.1029/2004GL020246, 2004.

Jensen, E. J., Toon, O. B., and Hamill, P.: Homogeneous Freezing Nucleation of Stratospheric Solution Droplets, Geophys. Res. Lett., 18, 1857-1860, 1991.

Knopf, D. A.: Do NAD and NAT form in liquid stratospheric aerosols by pseudoheterogeneous nucleation?, J. Phys. Chem. A, 110, 5745-5750, 2006.

Knopf, D. A., Koop, T., Luo, B. P., Weers, U. G., and Peter, T.: Homogeneous nucleation of NAD and NAT in liquid stratospheric aerosols: insufficient to explain denitrification, Atmos. Chem. Phys., 2, 207-214, 2002, http://www.atmos-chem-phys.net/2/207/2002/.

Koop, T., Luo, B., Tsias, A., and Peter, T.: Water activity as the determinant for homogeneous ice nucleation in aqueous solutions, Nature, 406, 611-614, 2000.

Larsen, N., Knudsen, B. M., Svendsen, S. H., Deshler, T., Rosen, J. M., Kivi, R., Weisser, C., Schreiner, J., Mauerberger, K., Cairo, F., Ovarlez, J., Oelhaf, H., and Spang, R.: Formation of solid particles in synoptic-scale Arctic PSCs in early winter 2002/2003, Atmos. Chem. Phys., 4, 2001-2013, 2004, http://www.atmos-chem-phys.net/4/2001/2004/.

Luo, B. P., Carslaw, K. S., Peter, T., and Clegg, S. L.: Vapor pressures of $\mathrm{H}_{2} \mathrm{SO}_{4} / \mathrm{HNO}_{3} / \mathrm{HCl} / \mathrm{HBr} / \mathrm{H}_{2} \mathrm{O}$ solutions to low stratospheric temperatures, Geophys. Res. Lett., 22, 247-250, 1995.

Luo, B. P., Voigt, C., Fueglistaler, S., and Peter, T.: Extreme NAT supersaturations in mountain wave ice PSCs: A clue to NAT formation, J. Geophys. Res., 108, 4441, doi:10.1029/2002JD003104, 2003.

Pagan, K. L., Tabazadeh, A., Drdla, K., Hervig, M. E., Eckermann, S. D., Browell, E. V., Legg, M. J., and Foschi, P. G.: Observational evidence against mountain-wave generation of ice nuclei as a prerequisite for the formation of three solid nitric acid polar stratospheric clouds observed in the Arctic in early December 1999, J. Geophys. Res., 109, D04312, doi:10.1029/2003JD003846, 2004.

Peter, T.: Microphysics and heterogeneous chemistry of polar stratospheric clouds, Ann. Rev. Phys. Chem., 48, 785-822, 1997.

Prenni, A. J., Onasch, T. B., Tisdale, R. T., Siefert, R. L., and Tolbert, M. A.: Composition-dependent freezing nucleation rates for $\mathrm{HNO}_{3} / \mathrm{H}_{2} \mathrm{O}$ aerosols resembling gravity-wave-perturbed stratospheric particles, J. Geophys. Res., 103, 28 439-28 450, 1998.

Salcedo, D., Molina, L. T., and Molina, M. J.: Nucleation rates of nitric acid dihydrate in $1: 2 \mathrm{HNO}_{3} / \mathrm{H}_{2} \mathrm{O}$ solutions at stratospheric temperatures, Geophys. Res. Lett., 27, 193-196, 2000.

Salcedo, D., Molina, L. T., and Molina, M. J.: Homogeneous freezing of concentrated aqueous nitric acid solutions at polar stratospheric temperatures, J. Phys. Chem. A, 105, 1433-1439, 2001.

Solomon, S.: Stratospheric ozone depletion: A review of concepts and history, Rev. Geophys., 37, 275-316, 1999.

Stetzer, O., Möhler, O., Wagner, R., Benz, S., Saathoff, H., Bunz, H., and Indris, O.: Homogeneous nucleation rates of nitric acid dihydrate (NAD) at simulated stratospheric conditions - Part I: Experimental results, Atmos. Chem. Phys., 6, 3023-3033, 2006, http://www.atmos-chem-phys.net/6/3023/2006/.

Tabazadeh, A.: Commentary on "Homogeneous nucleation of NAD and NAT in liquid stratospheric aerosols: insufficient to explain denitrification" by Knopf et al., Atmos. Chem. Phys., 3, 863865, 2003,

http://www.atmos-chem-phys.net/3/863/2003/.

Tabazadeh, A., Jensen, E. J., Toon, O. B., Drdla, K., and Schoeberl, M. R.: Role of the stratospheric polar freezing belt in denitrification, Science, 291, 2591-2594, 2001.

Tabazadeh, A., Djikaev, Y. S., Hamill, P., and Reiss, H.: Laboratory evidence for surface nucleation of solid polar stratospheric cloud particles, J. Phys. Chem. A, 106, 10 238-10246, 2002.

Tisdale, R. T., Middlebrook, A. M., Prenni, A. J., and Tolbert, M. A.: Crystallization kinetics of $\mathrm{HNO}_{3} / \mathrm{H}_{2} \mathrm{O}$ films representative of polar stratospheric clouds, J. Phys. Chem. A, 101, 21122119, 1997.

Tizek, H., Knözinger, E., and Grothe, H.: X-ray diffraction stud- 
ies on nitric acid dihydrate, Phys. Chem. Chem. Phys., 4, 51285134, 2002.

Turnbull, D.: Formation of crystal nuclei in liquid metals, J. Appl. Phys., 21, 1022-1028, 1950.

Voigt, C., Schreiner, J., Kohlmann, A., Zink, P., Mauersberger, K., Larsen, N., Deshler, T., Kroger, C., Rosen, J., Adriani, A., Cairo, F., Di Donfrancesco, G., Viterbini, M., Ovarlez, J., Ovarlez, H., David, C., and Dornbrack, A.: Nitric acid trihydrate (NAT) in polar stratospheric clouds, Science, 290, 1756-1758, 2000.

Voigt, C., Larsen, N., Deshler, T., Kröger, C., Schreiner, J., Mauersberger, K., Luo, B. P., Adriani, A., Cairo, F., Di Donfrancesco, G., Ovarlez, J., Ovarlez, H., Dörnbrack, A., Knudsen, B., and Rosen, J.: In situ mountain-wave polar stratospheric cloud measurements: Implications for nitric acid trihydrate formation, J. Geophys. Res., 108, 8331, doi:10.1029/2001JD001185, 2003.

Voigt, C., Schlager, H., Luo, B. P., Dörnbrack, A. D., Roiger, A., Stock, P., Curtius, J., Vössing, H., Borrmann, S., Davies, S., Konopka, P., Schiller, C., Shur, G., and Peter, T.: Nitric Acid Trihydrate (NAT) formation at low NAT supersaturation in Polar Stratospheric Clouds (PSCs), Atmos. Chem. Phys., 5, 13711380, 2005,

http://www.atmos-chem-phys.net/5/1371/2005/.
Wagner, R., Mangold, A., Möhler, O., Saathoff, H., Schnaiter, M., and Schurath, U.: A quantitative test of infrared optical constants for supercooled sulphuric and nitric acid droplet aerosols, Atmos. Chem. Phys., 3, 1147-1164, 2003, http://www.atmos-chem-phys.net/3/1147/2003/.

Wagner, R., Möhler, O., Saathoff, H., Stetzer, O., and Schurath, U.: Infrared spectrum of nitric acid dihydrate: Influence of particle shape, J. Phys. Chem. A, 109, 2572-2581, 2005.

Waibel, A. E., Peter, T., Carslaw, K. S., Oelhaf, H., Wetzel, G., Crutzen, P. J., Poschl, U., Tsias, A., Reimer, E., and Fischer, H.: Arctic ozone loss due to denitrification, Science, 283, 2064 2069, 1999. 